\title{
POLÍTICA PÚBLICA DE ASSISTÊNCIA SOCIAL: O MOMENTO DE CONSOLIDAÇÃO NO BRASIL
}

\author{
Márcia Maria Biondi Pinheiro ${ }^{1}$
}

\section{RESUMO}

O presente texto relata o momento atual da assistência social no Brasil no qual é criado o Ministério do Desenvolvimento Social e Combate à Fome (MDS), unificando as políticas de combate à fome, transferência de renda e assistência social. No campo da assistência social localiza o nascimento e as primeiras perspectivas da Política Nacional, cria o Sistema Único e propõe regulação institucional pela primeira vez no país de acordo com a Constituição Federal de 1988 e a Lei Orgânica de Assistência Social - LOAS.

PALAVRAS-CHAVE: Assistência Social; Política Nacional de Assistência Social; Conselho Nacional de Assistência Social; Sistema Único de Assistência Social; Proteção Social; Benefícios.

\section{INTRODUÇÃO}

No debate ocorrido em 14 de maio de 2004, promovido pelo Fórum Permanente de Extensão Universitária, organizado pelo Serviço Social da Unicamp, faziam-se públicas as primeiras elaborações da Secretaria Nacional de Assistência Social- SNAS do Ministério de Desenvolvimento Social e Combate à Fome - MDS.

Daquele momento até hoje, novembro de 2004, ocorreu a apresentação pela SNAS da proposta da Política Nacional de Assistência Social- PNAS- ao Conselho Nacional de Assistência Social (23 de junho). A partir daquele momento, o CNAS e a SNAS mobilizam as Secretarias, Fóruns, Conselhos estaduais e municipais, Núcleos de Estudos e Pesquisas das Universidades, enfim o movimento social em torno da assistência social no país para discussão da proposta preliminar. São colhidas inúmeras contribuições,

\footnotetext{
${ }^{1}$ Assistente Social doutoranda da Pontifícia Universidade Católica de São Paulo/ Assessora na Secretaria Nacional de Assistência Social do Ministério do Desenvolvimento Social e Combate à Fome/ Presidente do Conselho Nacional de Assistência Social.

\begin{tabular}{llllll}
\hline Serviço Social \& Saúde & Campinas & v. 4 & n. 4 & p. 1-156 & Maio 2005
\end{tabular}
}


acrescidas ao texto original e em 22 de setembro é aprovada no CNAS a proposta da nova PNAS. Em 14 de outubro, o texto final é aprovado, após analise de todos os destaques realizados pelos conselheiros.

Durante esse processo, o CNAS também sofre processos de mudanças. A nova composição da sociedade civil eleita pela primeira vez com autonomia (sem interferência direta do órgão gestor) toma posse, há modificação da representação governamental incluindo mais um membro do órgão gestor da política na sua composição, é eleita nova Presidência. Esta, assume compromissos de democratização do Conselho e a tarefa de zerar o estoque de cerca de 9.000 processos acumulados.

Esses eventos, fatos e acontecimentos relatados de forma sintética para esse texto, se constituem o cenário para as mudanças conjunturais que acontecem na área da assistência social hoje no Brasil. No entanto, se inserem num conjunto de respostas que o atual governo vem proporcionando, as quais se tentará localizar neste texto.

\section{AS POLÍTICAS SOCIAIS}

Para se comentar a conjuntura da política de assistência social no Brasil, é importante uma consideração a respeito das políticas sociais. Vieira (1992) analisa que historicamente essas são respostas às necessidades sociais, satisfazendo-as ou não. A política social expressa e carrega encargos do Estado, materializados em serviços de natureza pública e geral. Assim, a política de assistência social é resposta a necessidades sociais.

Outra observação a fazer é quanto ao caráter da sociedade brasileira. É extremamente autocrática, comandada por uma burguesia débil e subordinada aos pólos centrais do capitalismo, para a qual a sociedade civil restringe-se aos que detêm o poder econômico e as massas trabalhadoras, ameaça constante aos seus interesses de classe. Segundo Mazzeo, “A encarnação e a gênese da autocracia burguesa no Brasil é a política de Estado manipulador e alijador das massas populares (MAZZEO, 1989)”.

\begin{tabular}{llllll}
\hline Serviço Social \& Saúde & Campinas & v. 4 & n. 4 & p. 1-156 & Maio 2005
\end{tabular} 
Essas duas colocações acima se constituem em pano de fundo para reflexão do significado das políticas sociais e em especial a Política de Assistência Social no desafio de construção de um governo nacional democrático e popular.

Em primeiro lugar, é importante registrar que em 500 anos de exclusão social em nosso país, pela primeira vez foi expresso - numa orientação estratégica de governo, que se constitui no Plano Plurianual - PPA (2004-2007) -, que o objetivo, entre outros é “a inclusão social e a desconcentração da renda integrados ao crescimento do emprego e do produto".

Ainda segundo análises que fundamentam o PPA, as políticas de inclusão social e de redução das desigualdades, cujo objetivo é a justiça social, serão implementadas com base em políticas e programas que se distribuem nas dimensões sociais, econômicas, ambientais, regionais e de caráter democrático.

Assim, no âmbito social, a estratégia de governo "se rege pelo preceito dos direitos fundamentais da cidadania e da garantia da universalização do acesso a serviços públicos essenciais como a seguridade social (previdência, assistência social e saúde) e a educação. A priorização dos setores mais vulneráveis da população, buscando, por meio de políticas de caráter estrutural ou mesmo emergencial, a progressiva inclusão de mais de cinqüenta milhões de brasileiros que vivem em condições de extrema precariedade”.

“... é ampla a agenda de políticas sociais, complementares entre si, que dará suporte à estratégia do objetivo de inclusão social e redução das desigualdades sociais”.

Desta forma, acesso universal, garantia da qualidade dos serviços à população é agora premissa de governo. No entanto, esta premissa precisa ser construída. Muito antes da era neoliberal no Brasil, dominação burguesa e a necessidade de se evitar rupturas que favorecessem o protagonismo das classes trabalhadoras, sempre pautou a burguesia brasileira, que lutou pela manutenção do status quo, no máximo permitindo reformas "pelo alto” (MAZZEO, 1989).

A era neoliberal compreendeu a Seguridade Social baseada no seguro social, na previdência social, a saúde mercantilizada e a assistência social focalizada, emergencial, assistencialista (porque tuteladora). A ênfase foi em programas e projetos que, na grande maioria das vezes, não respeitava as necessidades dos Planos Municipais e Estaduais. Estes

\begin{tabular}{llllll}
\hline Serviço Social \& Saúde & Campinas & v. 4 & n. 4 & p. 1-156 & Maio 2005 \\
\hline
\end{tabular}


últimos, são os instrumentos de planejamento previstos no artigo 30 da Lei Orgânica da Assistência Social que devem dar conta da diversidade de cada Município e Estado.

A participação popular foi secundarizada, bem como os movimentos sociais. $\mathrm{O}$ respeito aos Conselhos apenas aconteceu no nível formal.

No entanto, o movimento social cresceu, comprovando que a Constituição Federal de 1988 estava no caminho correto ao propor uma nova forma de gestão. Tem-se hoje conselhos municipais e estaduais na área da assistência social, saúde e educação em quase todos Municípios brasileiros e nos Estados. Nem todos com a mesma maturidade política, havendo aqueles que se sujeitam aos ditames externos ao movimento popular, mas existindo os que se vêem investidos do verdadeiro sentido do controle social, da fiscalização e controle dos programas sociais.

Conferida pela Constituição de 1988 como direito social, o trânsito da política de Assistência Social para o campo de plena cidadania tem sido árduo.

O ano de $1993^{2}$ significou uma nova marca para essa Política, mas de lá para cá pouco se conquistou no avanço do terreno do público, da universalização. A noção de carência social a ser enfrentada pela sociedade manteve a política afastada do campo do Estado, que segundo Oliveira (1995:17) é a única possibilidade da ascensão da cidadania por setores sociais vulneráveis.

Esta situação de não política pública gerou inúmeros equívocos conceituais, legais e de financiamento, reduzindo a política a programas pontuais e sem perspectivas de universalização, com baixo controle social, pequena ou inexistente participação popular e, principalmente, dos usuários da política.

Pode-se afirmar que este círculo de baixa institucionalização tem sido quebrado por administrações com marcas de gestão democrática e com participação popular, que tenham também como objetivo a emancipação e o protagonismo da população.

Assim, embora declarada em 1988 como responsabilidade do Estado e como Política de Proteção Social no campo da seguridade social, num “conjunto integrado de ações de iniciativa dos poderes públicos e da sociedade destinada a assegurar os direitos

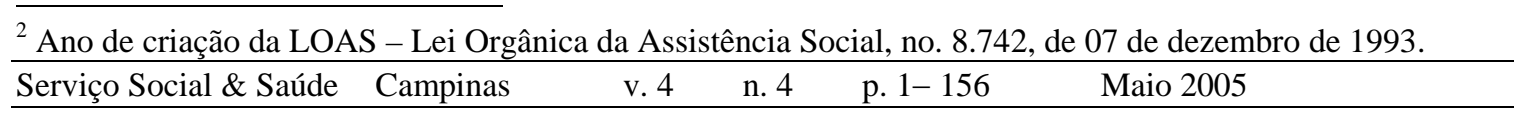


relativos à saúde, previdência e à Assistência Social” (CF.1988: artigo 194), na maioria das vezes, ainda significa apenas alívio da pobreza.

A falta do conceito de proteção social provocou que o formato de Assistência social se tornasse cada vez mais tênue no Brasil.

\section{NOVA CONJUNTURA BRASILEIRA}

É importante salientar o que está em curso no país, coordenado pelo Ministério de Desenvolvimento Social e Combate ‘a Fome (MDS) , através da Secretária Nacional de Assistência Social, um processo de modificações substanciais no campo sócio-assistencial brasileiro que deverá culminar com a implantação de um Sistema Único de Assistência Social em todo o território nacional. Esse processo está sendo possível pela decisão política do governo federal de uma formulação com novos princípios e bases e também pelo acúmulo técnico e político dos últimos 10 anos, a partir da promulgação da Loas, dos movimentos sociais desta área e de experiências de poder local em torno da construção e implantação da política de assistência social de fato pública e de direito.

O MDS iniciou suas atividades ( MP 163-de 23/01/2004) unificando, entre outras, três áreas sociais: a assistência social, a segurança alimentar e combate à fome e o programa bolsa família. No decreto que propiciou a unificação merece destaque o artigo $6^{0}$ : "Ficam extintos: -.... II - O Conselho do Programa Comunidade Solidária e a Secretaria Executiva do Programa Comunidade Solidária”.

Apontado por Pinheiro (2002) como um dos equívocos nas respostas de Fernando Henrique Cardoso ‘a questão social, o Programa Comunidade Solidária deslocou a assistência social do campo da política pública para o âmbito das decisões privadas e manteve a primeira dama na condução de ações sociais, pontuais, focalistas e sem nenhum controle social. Nenhuma discussão realizada com o Conselho Nacional de Assistência Social - CNAS, conforme previsto na Constituição. "É o social, sob esta ideologia, palco de manifesta bondade, sensibilidade e não de políticas públicas” (SPOSATI; 1995). 
Com estas marcas o MDS iniciou suas atividades rompendo com uma face conservadora de nosso passado recente, com decisões que alteram de maneira clara e objetiva as novas diretrizes para a Assistência Social no Brasil.

O MDS encontrou também uma situação estrutural bastante complexa em vários aspectos. Entre eles, um sistema financeiro burocratizado, arcaico, com mais de 20 anos sem revisão e reformulação. A inexistência de sistema de avaliação e monitoramento sobre o alcance cobertura e efetividade da política de assistência social no país - papel absolutamente fundamental do órgão gestor federal, além do déficit de servidores implicando no desenvolvimento e ações de caráter continuado por pessoal terceirizado, com contratação precária, levando ‘a rotatividade e perda de acúmulo técnico.

No entanto, a experiência existente, as discussões, avaliações e formulações no âmbito das universidades, dos gestores municipais e estaduais, de técnicos e trabalhadores sociais do serviço público e de entidades sociais, bem como conselheiros e militantes da área e, com a aprovação na lV Conferência Nacional de Assistência Social pela construção do Sistema Único de Assistência Social - SUAS, temos as bases para a transformação que está ocorrendo no campo desta política pública no Brasil.

O decreto 5.074 de 11 de maio de 2004, entre outros, expressa o compromisso de implantação e garantia de funcionamento de uma rede de Proteção Social organizado num sistema único de assistência social. Define o acesso aos direitos à Assistência Social visando sua universalização, buscando garantir e regular a implementação de serviços e programas de proteção básica e especial a fim de prevenir e reverter às situações de vulnerabilidade, riscos sociais e desvantagens visando a defesa dos direitos dos usuários. Propõe-se ainda a definir diretrizes para a prestação de serviços sócio-assistenciais no campo dos órgãos públicos, de entidades sociais e organizações não-governamentais.

É, a primeira vez, que há uma proposta de regulação nacional nesta área, que faz compromissos com o direito criando condições para o rompimento definitivo com o Assistencialismo.

A proposta atual cujo eixo é a proteção social possibilita a organização da política nacional superando uma abordagem de segmentos e estabelecendo que a Assistência Social ultrapasse o nível de responsabilidade individual, familiar e comunitária,

\begin{tabular}{llllll}
\hline Serviço Social \& Saúde & Campinas & v. 4 & n. 4 & p. 1-156 & Maio 2005 \\
\hline
\end{tabular}


assumindo o Estado a proteção social conforme prevista na Constituição Federal e na LOAS.

A Assistência Social afirma-se para além das provisões materiais que a marcaram e passa a ser também campo do reforço da auto-estima, da inserção social, da ampliação da resistência aos conflitos, de estímulo 'a participação social e comunitária, da maneira como previsto no Estatuto da Criança e do Adolescente, na Estatuto do Idoso e na Lei Orgânica da Assistência Social, reguladores do espírito da Constituição Cidadã Brasileira.

O Organograma da Secretaria Nacional de Assistência Social, do MDS, expressa o primeiro reordenamento institucional em consonância com a LOAS modificando a estruturação por segmentos e organizando- a por base de serviços de proteção.

Soma-se a isto, esforços no sentido de simplificação e padronização dos trâmites administrativos e a histórica conquista da dispensa de apresentação de Certidão Negativa de Débito - CND ao Instituto Nacional do Seguro Social - INSS quando se tratar de transferências relativas 'a Assistência Social, conquista que traduz o seu caráter continuado.

Expressão de mudanças e cumprimento do artigo 19 (LOAS) a SNAS propôs ao CNAS, a nova Política Nacional de Assistência Social, abrindo amplo debate nacional com a participação de pesquisadores, militantes, gestores, conselheiros, usuários e entidades sociais.

A nova política nacional expressa novas bases de organização, com matricialidade sócio-familiar, por descentralização político-administrativa e territorialização, pelo redesenho na relação Estado e Sociedade Civil, pelo aprimoramento no debate concorrente do financiamento pelos três entes federados, pelo protagonismo dos usuários, pela definição de uma política nacional de recursos humanos e a montagem de um sistema nacional de monitoramento e avaliação dos serviços prestados e de seu impacto.

$\mathrm{Na}$ estruturação do novo Ministério, essas diretrizes do ponto de vista da estruturação dos serviços a serem entregues 'a população, se organizam em Política de Proteção Social Básica, Política de Proteção Social Especial e Benefícios Sócioassistenciais.

Por Política de Proteção Social Básica entende-se todas as ações, serviços, programas e projetos que tenham "como objetivo assegurar direitos e propiciar a construção 
da autonomia das famílias, seus membros e indivíduos. Destina-se 'a população que vive em situação de vulnerabilidade social decorrente de pobreza, privação (ausência de renda, precário ou nulo acesso aos serviços públicos, dentre outros) e, ou fragilização de vínculos afetivos, relacionais e de pertencimento social (discriminação etária, étnicas, de gênero, por deficiência, dentre outras)."3

Por Política de Proteção Social Especial define-se uma "modalidade de atendimento assistencial destinada a famílias, seus membros e indivíduos que se encontram em situação de risco pessoal e social, por ocorrência de abandono, maus tratos físicos e, ou, psíquicos, abuso sexual, uso de substâncias psicoativas, cumprimento de medidas sócioeducativas, situação de rua, situação de trabalho infantil, dentre outras. São serviços que requerem acompanhamento individual e maior flexibilidade nas soluções protetivas. Têm estreita interface com o sistema de justiça...”

Os benefícios a que se referem a nova estruturação do Ministério são o Benefício de Prestação Continuada - BPC e os benefícios eventuais, este último previsto na LOAS e nunca antes regulado no Brasil.

Reitera-se aqui o já expresso em diversos pontos deste texto, que estas mudanças foram e estão sendo possíveis devido a diversos fatores. Um deles é a concretização de experiências municipais, de poder local, que foram conformadas pelos pressupostos que hoje informam a formulação nacional, tendo já um acúmulo prático de projetos, programas e serviços que respondam pela rede de proteção básica e especial que se quer ver implantada em todo o território nacional.

Os desafios colocados para a política estão expressos nela própria. Ressalta-se aqui os próximos passos. A construção do $1^{\circ}$.Plano Nacional que ofereça concretude ao pacto federativo no campo da PNAS e a conseqüente Norma Operacional (NOB) definindo os campos de atuação de cada esfera de governo e da sociedade na construção da proteção social brasileira.

${ }^{3}$ Conforme “ Política Nacional de Assistência Social - PNAS/MDS” . Página 50

\begin{tabular}{llllll}
\hline Serviço Social \& Saúde & Campinas & v. 4 & n. 4 & p. 1-156 & Maio 2005
\end{tabular} 


\begin{abstract}
This article describes the present time of the social assistance in Brazil created under the Ministry of Social Development and Hunger Combat (Ministério do Desenvolvimento Social e Combate à Fome) uniting the government policies against hunger, income transference and social assistance. In the field of social assistance, this paper deals with the first perspectives of National Policies, creates the Unified System (Sistema Único) and proposes institutional regulation for the first time in the country according to the Federal Constitution of 1988 and according to the Organic Law of Social Assistance (Lei Orgânica de Assistência Social - LOAS).
\end{abstract}

KEYWORDS: Social Assistance; Social Assistance National Policies; National Council of Social Assistance; Unified System of Social Assistance; Social Protection, Social Welfare.

\title{
REFERÊNCIAS BIBLIOGRÁFICAS
}

BRASIL. Ministério do Desenvolvimento Social e Combate à Fome. Secretaria Nacional de Assistência Social. Política Nacional de Assistência Social. Brasília, 2004.

MAZZEO, Carlos. Estado e Burguesia no Brasil, 1989.

OLIVEIRA, Francisco. A questão do Estado Vulnerabilidade Social - Cadernos ABONG - Outubro de 1995.

PINHEIRO, Márcia Maria Biondi. As subvenções sociais em Minas Gerais: a mediação parlamentar na política de assistência social. Dissertação (Mestrado) - Pontifícia Universidade Católica de São Paulo, 2002.

SPOSATI, Aldaíza. Cidadania e Comunidade Solidária. Revista Serviço Social \& Sociedade, 1997.

SPOSATI, Aldaíza. Sistema Único de Assistência Social, mimeo, 2004. 
